\title{
Editorial Expression of Concern: Long non-coding RNA Mirt2 relieves lipopolysaccharide-induced injury in PC12 cells by suppressing miR-429
}

\author{
Haibo $\mathrm{Li}^{1} \cdot \mathrm{Yu} \mathrm{Xu}{ }^{1} \cdot$ Guoxiu Wang ${ }^{2} \cdot$ Xuerong Chen ${ }^{1} \cdot$ Wenqing Liang ${ }^{1} \cdot$ Huawei $\mathrm{Ni}^{3}$
}

Received: 14 January 2021 / Accepted: 19 January 2021 / Published online: 1 March 2021

(C) University of Navarra 2021

Editorial Expression of Concern: $J$ Physiol Biochem 75, 403-413 (2019)

$$
\text { https://doi.org/10.1007/s13105-019-00691-7 }
$$

The Editors-in-Chief would like to alert readers that concerns have been raised regarding the data in this article [1]. The author did not provide raw data or details of ethics approval when requested. The corresponding author Huawei Ni contacted the journal to request article retraction but did not provide any explanation or reply to subsequent messages. The journal was also unable to contact the authors' institutions. Readers are advised to interpret the details of this article with caution.
The authors have not responded to any correspondence from the editors or publisher about this Editorial Expression of Concern.

\section{References}

Li, H., Xu, Y., Wang, G. et al. Long non-coding RNA Mirt2 relieves lipopolysaccharide-induced injury in PC12 cells by suppressing miR-429. J Physiol Biochem 75, 403-413 (2019). https://doi.org/ 10.1007/s13105-019-00691-7

Publisher's note Springer Nature remains neutral with regard to jurisdictional claims in published maps and institutional affiliations.
Huawei Ni

nihuawei0106@sina.com

1 Department of Orthopaedics, Shaoxing People's Hospital (Shaoxing Hospital of Zhejiang University), Shaoxing 312000, China

2 Department of Orthopaedics, Shenzhen University General Hospital, Shenzhen 518055, China

3 Department of Orthopaedics, The Affiliated Hospital of Hangzhou Normal University, No.126 Wenzhou Road, Hangzhou 310015, China 